\title{
INFLUÊNCIA DO TEMPO DE ARMAZENAGEM NA COR DOS GRÃOS DE CAFÉ PRÉ-PROCESSADOS POR "VIA SECA" E "VIA ÚMIDA"
}

\author{
PAULO CESAR AFONSO JÚNIOR ${ }^{1}$ \\ PAULO CESAR CORRÊA ${ }^{2}$
}

\begin{abstract}
RESUMO - Este trabalho foi desenvolvido com o objetivo de determinar a influência do período de armazenagem e do tipo de pré-processamento empregado no preparo do café (Coffea arabica L.), na coloração dos grãos beneficiados. O ensaio foi conduzido no delineamento inteiramente casualizado, com os tratamentos arranjados em um esquema fatorial com quatro períodos de armazenamento (0, 4, 8 e 12 meses) e dois tipos de pré-processamento (via seca e via úmida), com duas repetições. A determinação da cor dos grãos de café foi
\end{abstract}

realizada pela leitura direta de reflectância das coordenadas L, a e b em colorímetro tristímulo, empregando o sistema Hunter de cor. Concluiu-se que a armazenagem do café, em condições ambiente, afetou a coloração dos grãos de café, reduzindo, principalmente, a intensidade da cores verde e azul com o aumento do tempo de armazenamento, independentemente do tipo de pré-processamento empregado e que o sistema de pré-processamento por via úmida do café foi o que apresentou menor efeito na coloração dos grãos durante os oito primeiros meses de armazenamento.

TERMOS PARA IDEXAÇÃO: Café, armazenamento, qualidade, cor, Coffea arábica.

\section{INFLUENCE OF STORAGE TIME IN COLOR OF NATURAL AND WASHED COFFEE GRAINS}

\begin{abstract}
The main objective of this work was to determine the influence of the storage period and the type of pre-processing on the color of green coffee (Coffea arabica L.). The assay design was entirely randomized, with treatments arranged in a factorial scheme with four storage periods $(0,4,8$ and 12 months) and two types of pre-processing (natural and washed coffee), with two repetitions. The color of the coffee grains was determined by direct reading of
\end{abstract}

reflectance of coordinates $\mathbf{L}$, $\mathbf{a}$ and $\mathbf{b}$ in a tristimulus colorimeter, with the Hunter color system. It was concluded that the storage process, in atmosphere conditions, reduced the intensity of the green and blue colors of the coffee grains, with the increase of storage time, independently of the type of pre-processing employed and that the washing pre-processing presented the smaller effect on the color loss during the first eight months of storage.

INDEX TERMS: Coffee, storage, quality, color, Coffea arabica.

\section{INTRODUÇÃO}

O valor comercial dos grãos de café (Coffea arabica L.) está diretamente relacionado com sua qualidade. Os fatores que influenciam na sua qualidade incluem gênero, variedade, clima, época e forma de colheita, tipo de pré-processamento, sistema de secagem empregado e condições de armazenagem do produto, entre outras.

As características que definem a qualidade dos grãos de café e determinam sua aprovação podem ser agrupadas nas que dependem do aspecto físico dos mesmos, como: uniformidade, forma, tamanho e cor e nas que se referem a seu aroma e sabor. Dos aspectos físicos apresentados pelos grãos beneficiados, a cor tem maior importância que as demais características, uma vez que dela dependerá a rejeição ou aceitação do produto.

Vários são os fatores responsáveis pela modificação da cor dos grãos de café. Segundo Carvalho et al. (1997), a cor dos grãos de café está intimamente relacionada com a qualidade do produto. Sabe-se que, durante o armazenamento, os grãos têm sua cor alterada com o prolongamento do tempo de estocagem, passando da tonalidade verde-azulada, característica do produto de boa qualidade, à coloração marrom-clara e esbranquiçada, fenômeno conhecido como "branqueamento".

1. Engenheiro Agrícola, D.S., pesquisador da Embrapa-Café, 70770-901, Brasília, DF. paulo.junior@embrapa.br 2. Engenheiro Agrônomo, D.S., professor Adjunto no DEA-UFV, copace@mail.ufv.br 
Melo et al. (1980) atribuem a perda de cor dos grãos de café a reações oxidativas, de natureza enzimática ou não, envolvendo compostos fenólicos. Amorim (1978) observou que a descoloração ocorre principalmente em razão da desestruturação das membranas celulares, que podem ser causadas por agentes externos, como temperatura, umidade relativa do ar e injúrias mecânicas.

Bacchi (1962) menciona que a coloração dos grãos depende, em grande parte, da forma de preparo empregada no pré-processamento, do período e das condições de armazenagem do produto e do seu grau de umidade. Entretanto, Silva et al. (2001) armazenaram grãos de café em coco com diferentes níveis de umidade e verificaram, para a faixa de 11 a $13 \%$ de base úmida, que o produto não apresentou grandes alterações de cor e qualidade depois de 180 dias de armazenagem.

A casca e o pergaminho presentes no fruto de café pré-processado em sua forma integral (via seca) também podem atuar como agentes protetores contra variações ambientais, tornando-o menos sujeito à deterioração, quando comparado ao produto pré-processado por via úmida (descascado) (MATIELLO, 1991). O autor cita, ainda, que o café obtido por via seca, quando armazenado em condições adequadas, com umidade de 11 a $12 \%$ b.u., mantém sua cor inicial e conserva-se bem durante vários anos. Já o produto pré-processado por via úmida, sujeito a injúrias mecânicas, pode perder sua coloração original e branquear mais rapidamente durante o armazenamento. Godinho et al. (2000) verificaram o efeito protetor da casca e do pergaminho no grão, os quais evitaram variações na cor do produto armazenado em coco, quando comparado com o café estocado já beneficiado.

Evidências de que a cor dos grãos de café se correlaciona com as condições de armazenagem é muito enfatizada por alguns autores (OLIVEIRA, 1995; VILELA et al., 2000). Esses pesquisadores constataram que a temperatura e a umidade relativa do ambiente de armazenagem, além da iluminação, influenciam na mudança de coloração dos grãos de café, sendo menos freqüentes essas alterações em locais de baixa temperatura e umidade relativa. Experimentos realizados por Lopes et al. (2000), analisando o efeito da luz e de diferentes faixas espectrais sobre a qualidade de grãos de café beneficiado, durante o armazenamento, mostraram ser a luz transmitida por filtro azul a mais prejudicial à qualidade do café, por apresentar maiores níveis de energia.

Os atuais procedimentos de avaliação da cor dos grãos de café levam em consideração procedimentos subjetivos, limitando-se, apenas, a uma série de compa- rações visuais do produto, tendo como desvantagem o fato de os resultados obtidos serem influenciados pelo julgamento e pelas limitações do observador (LOPES et al., 1998). Alguns autores afirmam que são necessários métodos objetivos (espectrofotometria e colorimetria) para avaliação da cor de produtos agrícolas, por permitirem uma melhor definição das condições de iluminação e observação (KRAMER e TWIGG, 1970; FERREIRA, 1981).

Tendo em vista ser a cor dos grãos de café um importante indicativo da qualidade do produto, e a necessidade de informações sobre o efeito dos métodos de processamento sobre a cor do produto armazenado, este trabalho foi desenvolvido com o objetivo de avaliar o efeito do préprocessamento, por via seca e via úmida, sobre a cor dos grãos de café beneficiados, durante o armazenamento.

\section{MATERIAL E MÉTODOS}

O presente trabalho foi realizado no Laboratório de Armazenamento e Pré-processamento de Produtos Vegetais do Departamento de Engenharia Agrícola da Universidade Federal de Viçosa e no Laboratório de Propriedades Físicas e Avaliação de Qualidade de Produtos Agrícolas, localizado no Centro Nacional de Treinamento em Armazenagem - CENTREINAR, em Viçosa, MG.

Foram colhidos manualmente frutos de café da variedade Catuaí, provenientes de diferentes propriedades do município de Viçosa, MG. Esses frutos foram divididos em dois lotes. O primeiro lote foi composto de café em coco (forma integral), pré-processado por via seca. O segundo lote foi formado de café descascado, pré-processado por via úmida.

Para secagem do produto, foi utilizada uma unidade condicionadora de ar do tipo "Aminco-Aire", dotada de dispositivos para o controle da temperatura e umidade relativa do ar de secagem. Para realização do processo de secagem, o fluxo de ar, a temperatura e a umidade relativa do ar de secagem foram mantidos constante em $13 \mathrm{~m}^{3} \cdot \mathrm{min}^{-1} \cdot \mathrm{m}^{-2}, 40^{\circ} \mathrm{C}$ e $50 \%$, respectivamente. Ao término da etapa de secagem $(12 \%$ base úmida), para cada tratamento, o produto foi mantido em ambiente desumidificado até atingir a temperatura ambiente, sendo, em seguida, acondicionado em sacos de papel e armazenado em condições ambiente, registrando, em termohigrógrafo, os dados de temperatura e umidade relativa durante o período de estocagem. $\mathrm{O}$ teor de água do produto foi determinado pelo método da estufa, $105 \pm 3^{\circ} \mathrm{C}$, por 24 horas (BRASIL, 1992).

Os tratamentos foram dispostos em esquema fatorial $4 \times 2$, com quatro períodos de armazenagem $(0$, 
8 e 12 meses) e duas formas de pré-processamento (coco e descascado), com duas repetições para cada tratamento. A cada quatro meses, para cada repetição de todos os tratamentos, foram retiradas amostras de $100 \mathrm{~g}$ e realizadas avaliações quanto à cor e ao teor de água dos grãos de café.

Para avaliação da cor do material armazenado, o produto foi beneficiado manualmente (retirando-se a casca e o pergaminho) e a determinação da cor dos grãos de café foi realizada pela leitura direta de reflectância das coordenadas $\mathbf{L}$, a e b em colorímetro tristímulo (iluminante $10 \%$ D65), empregando o sistema Hunter de cor, sendo $\mathbf{L}$ relativo ao branco e negro (luminância); a, ao vermelho e verde, e b, ao amarelo e azul (Figura 1). Para cada repetição, de todos os tratamentos analisados, foi utilizada a média de três repetições para avaliação da cor dos grãos beneficiados.

Utilizando-se os valores das coordenadas $\mathbf{L}, \mathbf{a}$ e b, foram calculados os valores do índice colorimétrico diferença de cor $(\Delta \mathbf{E})$, de acordo com a expressão (LOZANO, 1978):

$$
\Delta \mathbf{E}=\sqrt{\Delta \mathbf{L}^{2}+\Delta \mathbf{a}^{2}+\Delta \mathbf{b}^{2}}
$$

Para o cálculo desse índice colorimétrico, em função da cor dos grãos de café no início de cada período de armazenagem, foram empregados os seguintes elementos na equação 1 :

$$
\begin{aligned}
\Delta \mathbf{E}_{\mathrm{p}} & =\text { diferença de cor do período; } \\
\Delta \mathbf{L} & =\mathrm{L}(\mathrm{t})-\mathrm{L}(\mathrm{t}-\mathrm{i}) ; \\
\Delta \mathbf{a} & =\mathrm{a}(\mathrm{t})-\mathrm{a}(\mathrm{t}-\mathrm{i}) ; \\
\Delta \mathbf{b} & =\mathrm{b}(\mathrm{t})-\mathrm{b}(\mathrm{t}-\mathrm{i}) ; \\
\mathrm{t} & =\text { período de armazenamento (meses) } \\
\mathrm{i} & =\text { período anterior (meses). }
\end{aligned}
$$

Já para o cálculo da diferença de cor (eq. 1), em função da cor inicial dos grãos de café, foram utilizados:

$$
\begin{aligned}
\Delta \mathbf{E}_{0} & =\text { diferença de cor; } \\
\Delta \mathbf{L} & =\mathrm{L}(\mathrm{t})-\mathrm{L}(0) ; \\
\Delta \mathbf{a} & =\mathrm{a}(\mathrm{t})-\mathrm{a}(0) ; \\
\Delta \mathbf{b} & =\mathrm{b}(\mathrm{t})-\mathrm{b}(0) ; \\
\mathrm{t} & =\text { período de armazenamento (meses); } \\
0 & =\text { período inicial (mês } 0) .
\end{aligned}
$$

Para estudar o efeito do período de armazenagem e do tipo de pré-processamento sobre as coordenadas de Hunter para avaliação da cor dos grãos de café, os dados experimentais obtidos foram submetidos à análise de regressão. A escolha do modelo de predição baseou-se na magnitude dos coeficientes de determinação e na significância dos coeficientes das equações ajustadas.

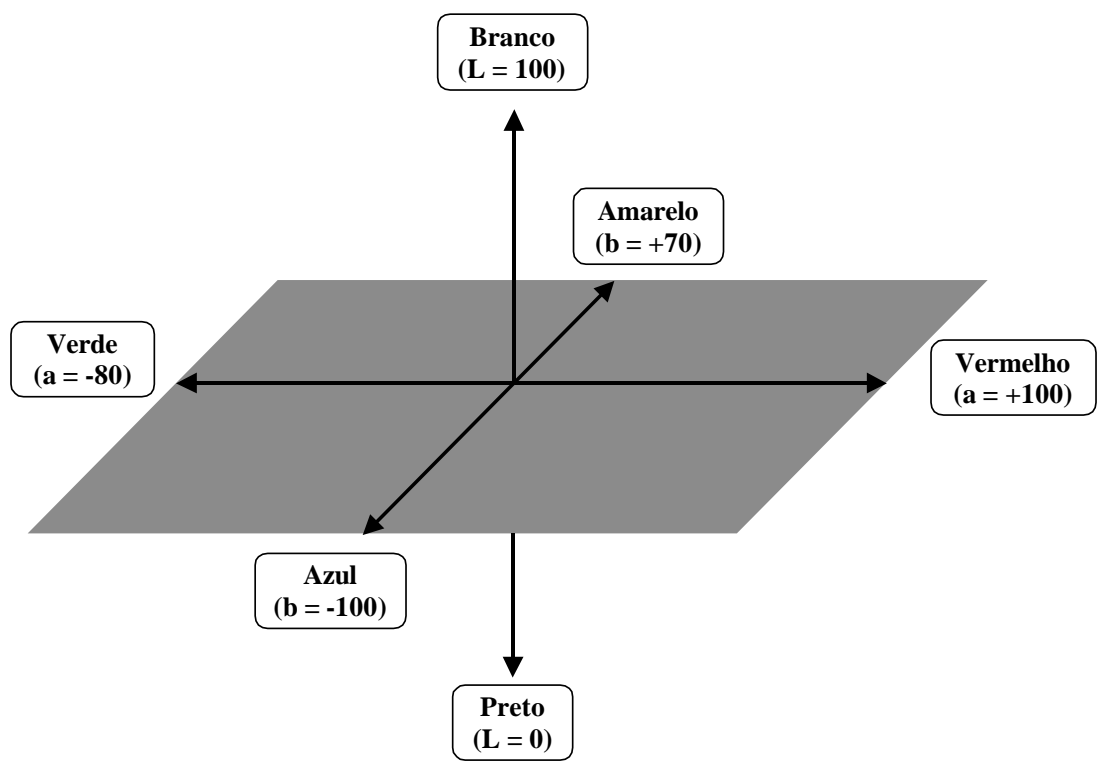

FIGURA 1 - Representação esquemática do sistema de coordenadas de Hunter para avaliação de cor. 


\section{RESULTADOS E DISCUSÃO}

Na Figura 2, encontram-se os valores médios dos teores de água dos grãos de café, para cada tipo de préprocessamento analisado, em função do tempo de armazenagem. A variação desse parâmetro está intimamente relacionada com as alterações de temperatura e umidade relativa do ambiente de armazenamento (Figura 3).

Observa-se, de modo geral, a existência de pequenas diferenças entre os valores de teor de umidade dos grãos de café, o que indica uma pequena influência da variação dos fatores ambientais sobre essa variável. Os teores de umidade das amostras variaram entre $11 \mathrm{e}$ $13 \%$ de base úmida, o que, de acordo com Silva et al. (2001), encontra-se dentro da faixa adequada para armazenagem segura do produto.

As equações de predição ajustadas para as coordenadas $\mathbf{L}$, a e b estão apresentadas na Tabela 1, para o produto pré-processado por via seca e via úmida, respectivamente. Observa-se, de modo geral, que a alteração dos valores das coordenadas $\mathbf{L}$, a e b foram relevantes na avaliação da qualidade da cor dos grãos de café, independentemente do tipo de pré-processamento analisado, com exceção dos valores de $\mathbf{L}$, quando os grãos foram préprocessados via seca. Verifica-se o aumento desses valores durante o armazenamento, tanto para o produto em sua forma integral como descascado, indicando tendência ao branqueamento do produto com o prolongamento do período de armazenagem, como constatado por diversos pesquisadores (MELO et al., 1980; CARVALHO et al., 1997).

Na Figura 4 estão apresentados os gráficos para predizer as alterações ocorridas nas coordenadas $\mathbf{L}, \mathbf{a}$ e b dos grãos de café pré-processados por via seca e via úmida, em função do tempo de estocagem. Observa-se, de modo geral, uma tendência de aumento dos valores das coordenadas avaliadas com a elevação do período de armazenamento, exceto para coordenada $\mathbf{L}$ (Figura 4, A) do produto em sua forma integral, que apresentou comportamento diferente ao observado para as demais coordenadas, não se alterando significativamente com o aumento do tempo de armazenagem. Isso sugere que a casca presente no café pré-processado por via seca contribui para sua proteção, reduzindo os possíveis efeitos ambientais sobre a luminância do produto armazenado. Resultados semelhantes sobre o efeito protetor da casca do produto também foram observados por outros autores (MATIELLO, 1991; GODINHO et al., 2000). Analisando-se, ainda, o comportamento da coordenada $\mathbf{L}$, observa-se que o efeito de clareamento dos grãos apresentou-se mais aparente para o material pré-processado por via úmida. Nota-se, também, o aumento dos valores dessa coordenada com o prolongamento do tempo de armazenagem, indicando a influência desse fator sobre a luminância dos grãos de café descascado.

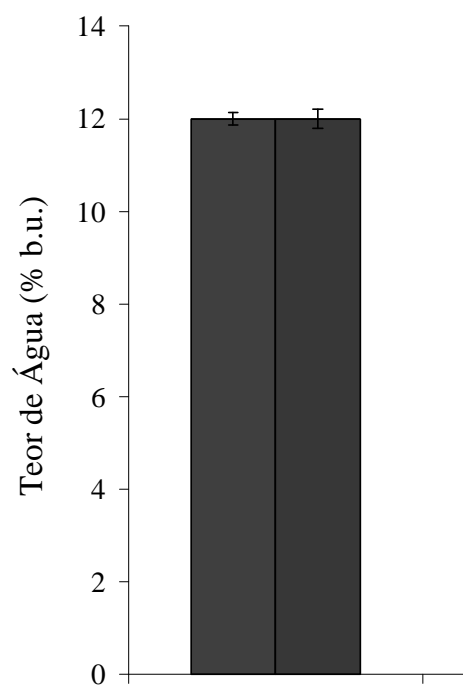

0

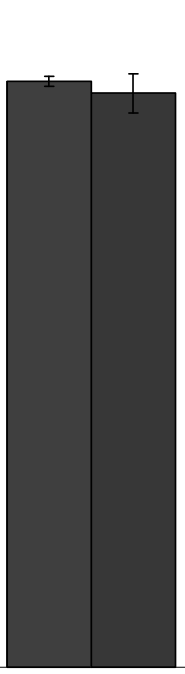

4

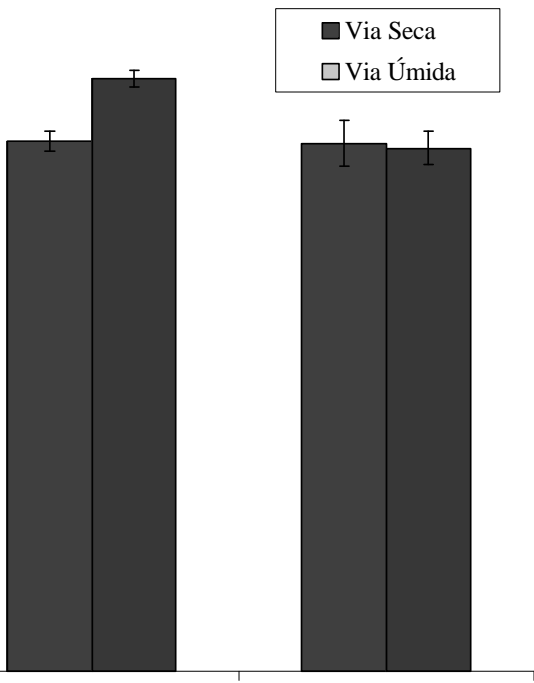

8

12

Período de Armazenagem (meses)

FIGURA 2 - Valores médios de teor de água (\% b.u.) dos grãos de café, em função do tipo de pré-processamento e do tempo de armazenagem. Barras representam os erros-padrões das médias.

Ciênc. agrotec., Lavras. V.27, n.6, p.1268-1276, nov./dez., 2003 


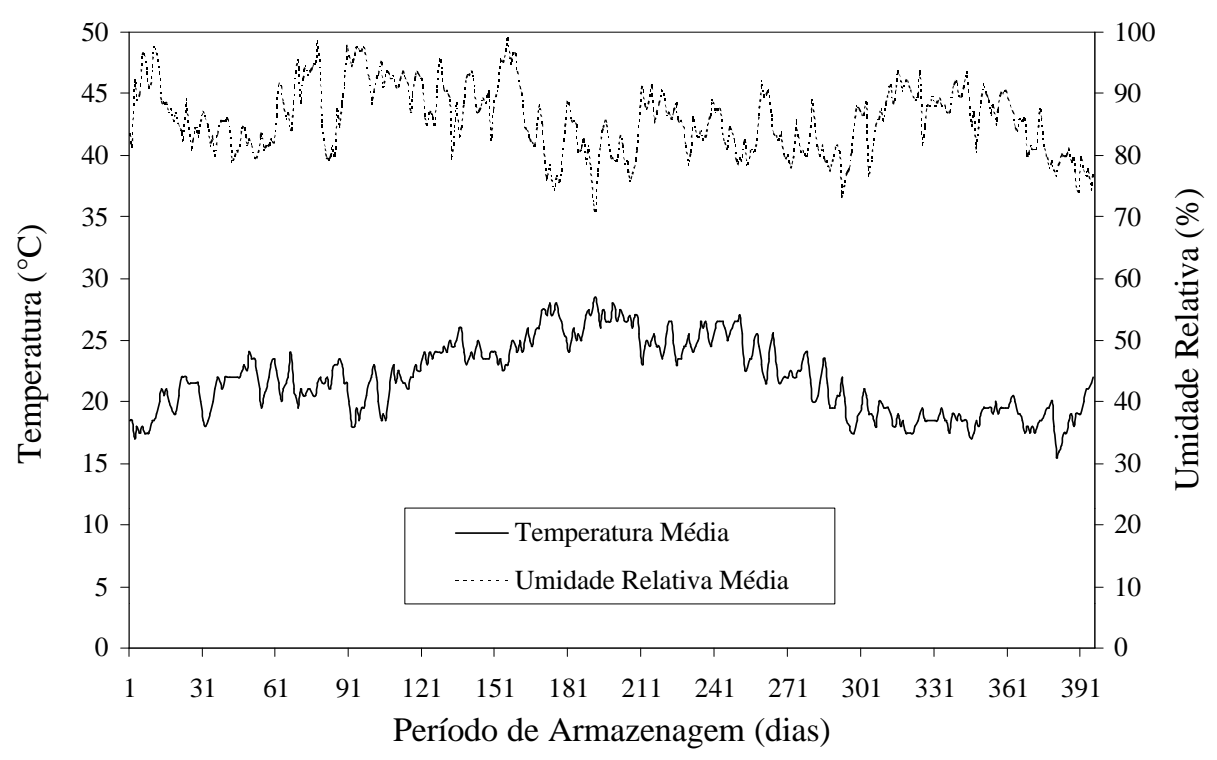

FIGURA 3 - Médias diárias de temperatura e umidade relativa do ar ambiente, durante o armazenamento dos grãos de café em condições não controladas.

TABELA 1 - Equações de regressão ajustada e os coeficientes de determinação para as coordenadas $\mathbf{L}$, a e b do sistema de Hunter para avaliação da cor de grãos de café pré-processados por via seca e via úmida, em função do tempo de armazenamento ( $\mathrm{T})$.

Coordenada do

Sistema Hunter

Equação de Regressão

Via Seca (coco)

L

a

b

L

b

$$
\hat{\mathrm{L}}=35,43
$$

$\hat{\mathrm{b}}=11,262+0,147^{* *} \cdot \mathrm{T}$

Via Úmida (descascado)

$\hat{\mathrm{L}}=37,503+0,271^{* *} \mathrm{~T}$

$\hat{\mathrm{a}}=1,110+0,039^{* *} \cdot \mathrm{T}$

$\hat{b}=9,763+0,160^{* *} \cdot T$ $\hat{\mathrm{a}}=2,462+0,117^{* *} \cdot \mathrm{T}$
Coeficiente de Determinação$$
\text { n.s. }
$$

$0,987^{++}$

$0,949^{++}$

\footnotetext{
${ }^{++}$Significativo a $1 \%$ de probabilidade, pelo teste $\mathbf{F}$. ** Significativo a $1 \%$ de probabilidade pelo teste $t$. n.s. não significativo.
} 


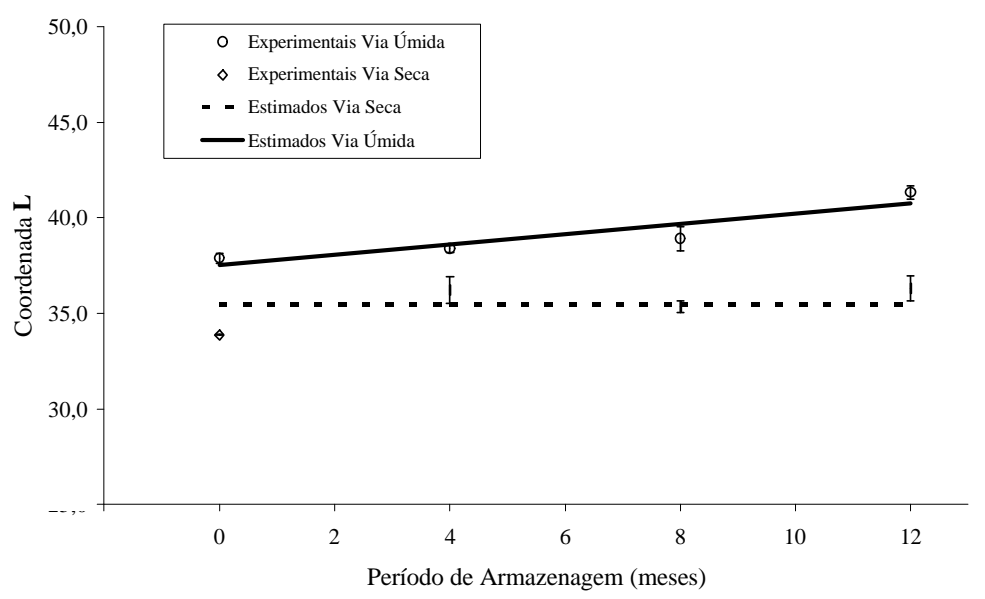

(A)

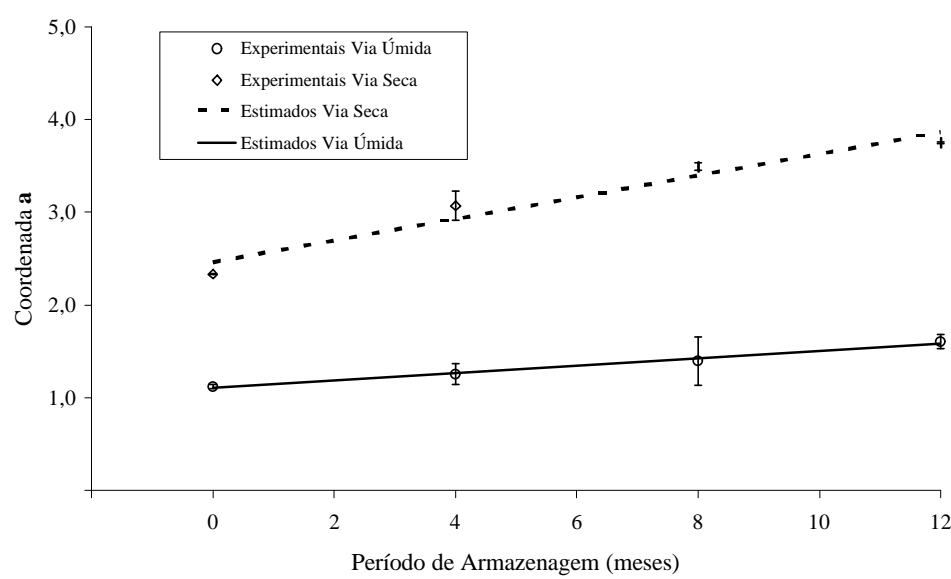

(B)

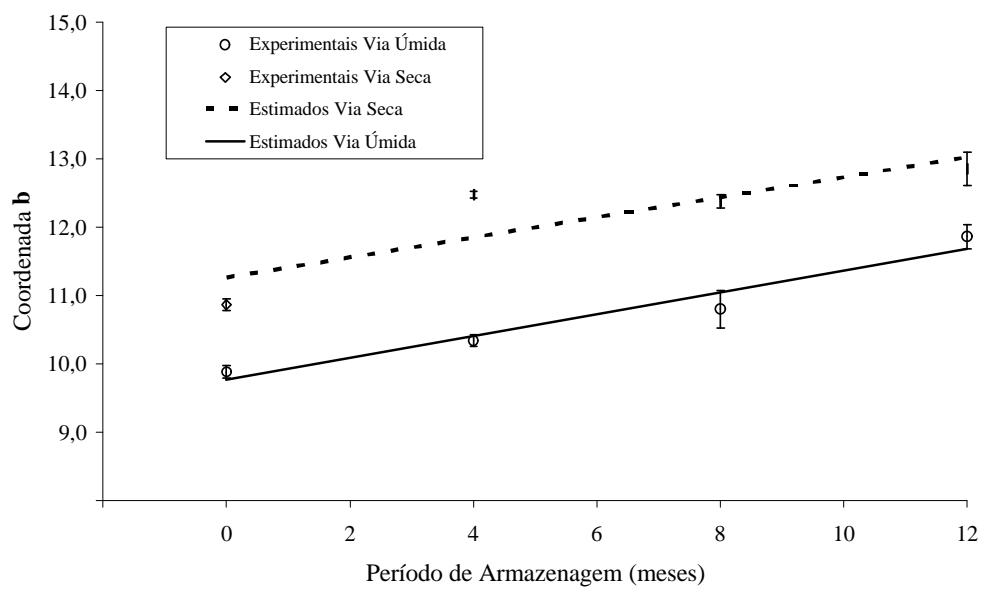

(C)

FIGURA 4 - Valores experimentais e estimados das coordenadas L (A), a (B) e b (C) do sistema Hunter para avaliação da cor dos grãos de café pré-processados por via seca e via úmida, em função do tempo de armazenamento (T). Barras representam os erros-padrões das médias. 
Embora as coordenadas a e b (Figura 4, B e C) tenham apresentado aumento de seus valores durante $\mathrm{O}$ armazenamento dos grãos provenientes do préprocessamento via seca e úmida, indicando uma tendência de afastamento das colorações verde (> a) e azul $(>\mathbf{b})$, verifica-se que os grãos de café produzidos por via úmida apresentaram maior intensidade das cores verde $(<\mathbf{a})$ e azul $(<\mathbf{b})$, característica do produto de melhor qualidade (BACCHI, 1962), quando comparados com o produto pré-processado por via seca. A retirada da casca e parte da mucilagem do fruto do café pelo preparo via úmida parece contribuir positivamente para a redução dos efeitos dos possíveis fatores desfavoráveis ao armazenamento do produto sobre as coordenadas cromáticas a e b.

Os resultados da análise conjunta das alterações das coordenadas de cromaticidade e de luminância dos grãos de café beneficiados nos diferentes tipos de préprocessamentos estudados, durante o armazenamento, são apresentados nas Figuras 5 e 6.

$\mathrm{Na}$ Figura 5 são apresentados os valores de diferença de cor $\left(\Delta \mathrm{E}_{\mathrm{p}}\right)$, calculados independentemente para cada período de armazenagem e tipo de préprocessamento empregado. Verifica-se que inicialmente os grãos de café obtidos por via seca apresentaram uma acentuada alteração de sua cor original, até o quarto de mês de armazenagem, quando comparados com o produto preparado por via úmida. Após esse período, apresentaram uma menor diferenciação de cor, apresentando tendência à estabilização dos valores de diferença de cor dos grãos conservados em sua forma integral. No entanto, comportamento contrário se observa para o material pré-processado por via úmida, que apresentou um pequeno crescimento no início do período de armazenamento, para, a partir do oitavo mês, apresentar um comportamento mais acentuado de variação da cor do produto. Observa-se, ainda, que embora a alteração dos valores da coordenada $\mathbf{L}$, durante o armazenamento, tenha sido mais relevante para o produto descascado, como já mencionado anteriormente, as modificações das coordenadas cromáticas a e b com o tempo foram mais importantes para a redução da qualidade da cor do produto armazenado em sua forma integral.

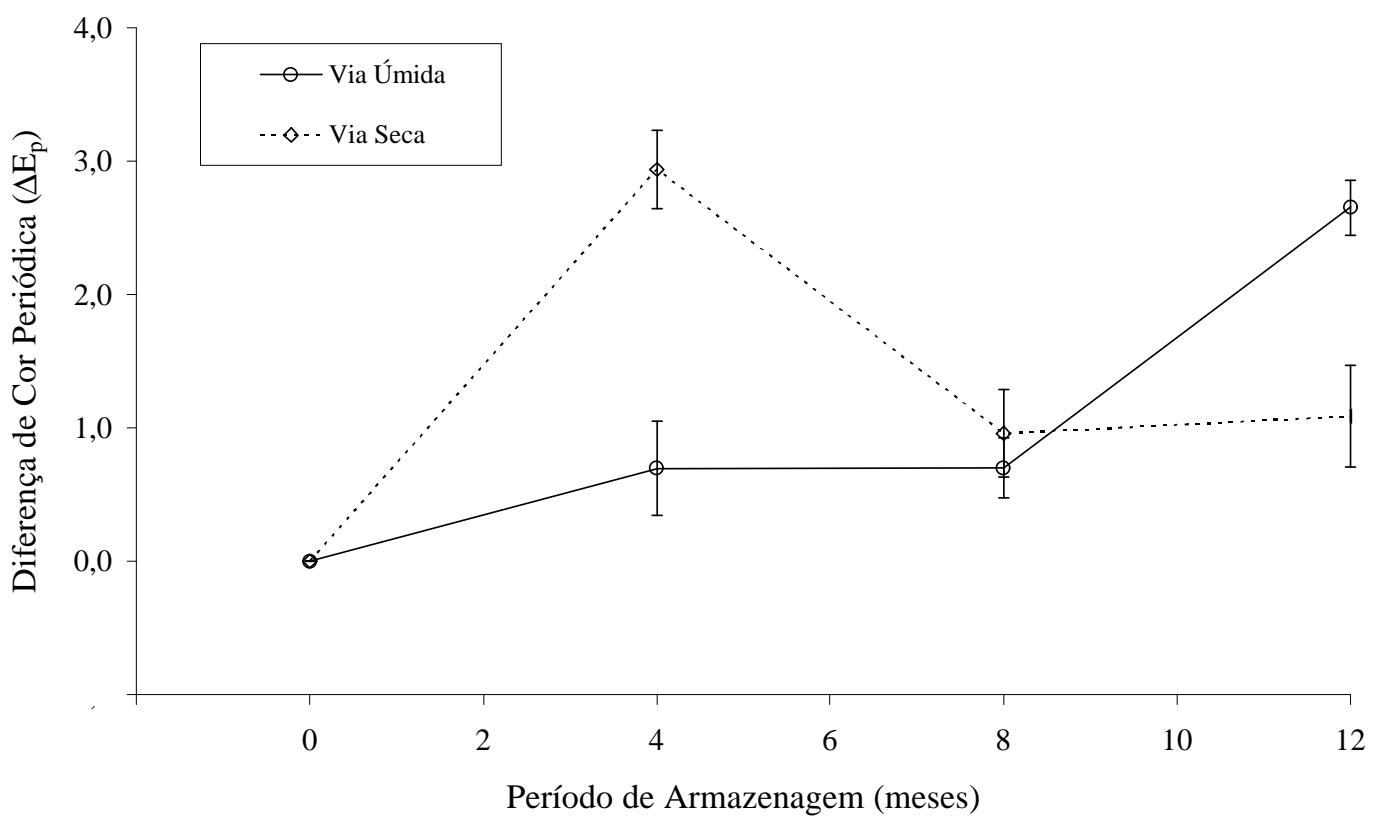

FIGURA 5 - Valores de diferença de cor $\left(\Delta \mathrm{E}_{\mathrm{p}}\right)$ dos grãos de café pré-processados por via seca e via úmida, para cada período de armazenamento. Barras representam os erros-padrões das médias. 


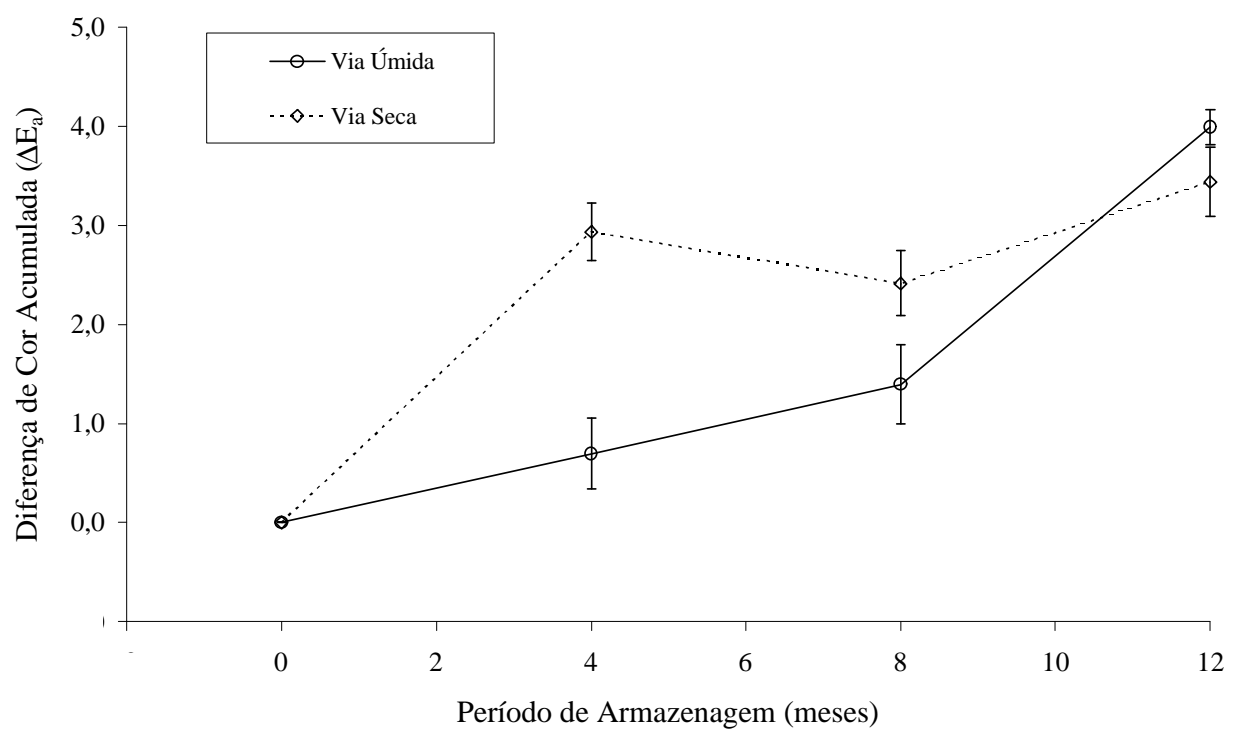

FIGURA 6 - Valores de diferença de cor $\left(\Delta \mathrm{E}_{0}\right)$ dos grãos de café pré-processados por via seca e via úmida, em relação à cor inicial do produto, para o período de armazenamento de 12 meses. Barras representam os erros-padrões das médias.

Os valores calculados do índice colorimétrico diferença de cor $\left(\Delta \mathrm{E}_{0}\right)$, em relação à cor inicial do produto, para o período de estocagem e tipos de préprocessamento do produto, são mostrados na Figura 6. Levando-se em consideração a cor do produto no inicio do processo de armazenagem e a diferença de cor ao longo do período de armazenamento, observa-se a ocorrência de uma evolução na perda da cor original dos grãos de café com o aumento do tempo de armazenagem, para os cafés preparados por via seca e via úmida. Vale ressaltar, no entanto, que, no início da armazenagem, a diferença da cor dos grãos pré-processados por via seca, em relação à sua cor original, foi mais acentuada que a dos grãos obtidos por via úmida, tendendo essa diferença a reduzir-se com o prolongamento da armazenagem, ocorrendo o inverso para o produto obtido por via úmida, que apresentou uma alteração mais acentuada da cor ao final do período de armazenamento estudado. Fato que parece indicar a existência de efeitos latentes do processo de descascamento dos frutos do café durante seu pré-processamento sobre a coloração dos grãos.

Portanto, dos resultados obtidos para as coordenadas do sistema Hunter de avaliação da cor (Figura 4) e para as diferenças de cor (Figura 5 e 6), pode-se inferir que os grãos de café pré-processados por via seca tendem a uma maior perda de sua coloração durante o período de armazenagem, quando comparados com o material pré-processado por via úmida, principalmente no início do armazenamento. De acordo com vários pesquisadores, a perda de coloração pode estar associada à redução da qualidade do produto (OLIVEIRA, 1995; VILELA et al., 2000). Infere-se com isso, a necessidade de maiores cuidados durante o armazenamento do produto, com relação aos possíveis fatores responsáveis pela alteração da cor dos grãos de café.

\section{CONCLUSÕES}

a) A intensidade das cores verde e azul dos grãos de café foi afetada durante o armazenamento, independentemente do tipo de pré-processamento empregado;

b) A luminância (coordenada $\mathbf{L}$ do sistema Hunter) dos grãos de café pré-processados por via seca não foi afetada durante o armazenamento;

c) os grãos de café pré-processados por via úmida apresentaram-se mais estáveis com relação à sua coloração, quando comparados com os obtidos pelo préprocessamento via seca, durante os oito primeiros meses de armazenamento.

\section{AGRADECIMENTOS}

À FAPEMIG e à EMBRAPA (PNP\&D - Café), pelo auxílio financeiro concedido para a realização deste trabalho.

Ciênc. agrotec., Lavras. V.27, n.6, p.1268-1276, nov./dez., 2003 


\section{REFERÊNCIAS BIBLIOGRÁFICAS}

AMORIM, H. V. Aspectos bioquímicos e histoquímicos do grão de café verde relacionados com a deterioração de qualidade. 1978. 85 f. Tese (Livre Docência) - Escola Superior de Agricultura Luiz de Queiroz, Piracicaba, 1978.

BACCHI, O. O branqueamento dos grãos de café. Bragantia, Campinas, v. 21, n. 28, p. 467-468, 1962.

BRASIL. Ministério da Agricultura e Reforma Agrária. Regras para análise de sementes. Brasília: DNDV/CLAV, 1992. 365 p.

CARVALHO, V. D.; CHAGAS, S. J. R.; SOUZA, S. M. C. Fatores que afetam a qualidade do café. Informe Agropecuário, Belo Horizonte, v. 18, n. 187, p. 5-20, 1997.

FERREIRA, V. L. P. Princípios e aplicações da calorimetria em alimentos. Campinas: Instituto de Tecnologia de Alimentos, 1981. 86 p. (Instruções Técnicas, 19).

GODINHO, R. P.; VILELA, E. R.; OLIVEIRA, G. A.; CHAGAS, S. J. R. Variações na cor e na composição química do café (Coffea arabica L.) armazenado em coco e beneficiado. Revista Brasileira de Armazenamento, Viçosa, n. 1, p. 38-43, 2000. Edição Especial.

KRAMER, A.; TWIGG, B. A. Quality control for the food industry. 3. ed. Westport: AVI, 1970. 556 p.

LOPES, R. P.; HARA, T.; SILVA, J. S. Avaliação da qualidade de grãos de café pela colorimetria. Engenharia na Agricultura, Viçosa, v. 6, n. 3, p. 160-169, 1998.
LOPES, R. P.; HARA, T.; SILVA, J. S.; RIEDEL, B. Efeito da luz na qualidade (cor e bebida) de grãos de café beneficiados (Coffea arabica L.) durante a armazenagem. Revista Brasileira de Armazenamento, Viçosa, n. 1, p. 9-17, 2000. Edição Especial.

LOZANO, R. D. El color y su medición. Buenos Aires: Américalee, 1978. 640 p.

MATIELLO, J. B. O café do cultivo ao consumo. São Paulo: Globo, 1991. 320 p.

MELO, M.; FAZUOLI, L. C.; TEIXEIRA, A. A.; AMORIM, H. V. Alterações físicas, químicas e organolépticas em grãos de café armazenados. Ciência e Cultura, São Paulo, v. 32, n. 4, p. 468-471, 1980.

OLIVEIRA, M. V. Efeito do armazenamento no branqueamento de grãos de café beneficiado: modelagem matemática do processo. 1995. 99 f. Dissertação (Mestrado) - Escola Superior de Agricultura de Lavras, Lavras, 1995.

SILVA, R. P. G.; VILELA, E. R.; PEREIRA, R. G. F. A.; BORÉM, F. M. Qualidade de grãos de café (Coffea arabica L.) armazenados em coco, com diferentes níveis de umidade. Revista Brasileira de Armazenamento, Viçosa, n. 3, p. 3-10, 2001. Edição Especial.

VILELA, E. R.; CHANDRA, P. K.; OLIVEIRA, G. A. Efeito da temperatura e umidade relativa no branqueamento de grãos de café. Revista Brasileira de Armazenamento, Viçosa, n. 1, p. 31-37, 2000. Edição Especial 